\title{
Os experts e a produção de saberes para a docência: primeiros estudos do acervo Lydia Lamparelli
}

DOI10.26512/lc.v25i0.23109

André Francisco de Almeida ${ }^{1}$
Wagner Rodrigues Valente

\section{Resumo}

Este artigo apresenta resultados parciais de projeto de pesquisa intitulado Os experts e a aritmética para ensinar nos primeiros anos escolares, São Paulo (19611996). Abordar o saber profissional do professor que ensina matemática é o tema desse projeto, que busca tornar inteligível o papel de experts na sistematização de uma aritmética para ensinar. Este texto traz as primeiras análises da produção de Lydia Lamparelli, constituída como expert, a partir de referências bibliográficas tomadas para este estudo. Os primeiros resultados revelam possibilidades que acervos pessoais podem dar à caracterização do saber profissional do professor que ensina matemática.

Palavras-chave: Saber para ensinar. Aritmética. Lydia Lamparelli. Expert. Arquivos pessoais.

\section{Resumen}

1 Doutorando em Ciências pela Universidade Federal de São Paulo, Campus Guarulhos, SP. E-mail: afdealmeida@ gmail.com

2 Professor Livre Docente do Departamento de Educação da Escola de Filosofia, Letras e Ciências Humanas da UNIFESP, Campus Guarulhos, SP. Coordenador do GHEMAT-SP, www.ghemat.com.br E-mail: ghemat.contato@ gmail.com 
Este artículo presenta resultados parciales de proyecto de investigación titulado Los expertos y la aritmética para enseñar en los primeros años escolares, São Paulo (19611996). Abordar el saber profesional del profesor que enseña matemáticas es el tema de ese proyecto que busca hacer inteligible el papel de expertos en la sistematización de una aritmética para enseñar. Este texto trae los primeros análisis de la producción de Lydia Lamparelli, constituida como experto, a partir de referencias bibliográficas tomadas para este estudio. Los primeros resultados revelan posibilidades que acervos personales pueden dar a la caracterización del saber profesional del profesor que enseña matemáticas.

Palabras clave: Saber para enseñar. Aritmética. Lydia Lamparelli. Experto. Archivos personales.

\section{Abstract}

This article presents partial results of a research project entitled The experts and arithmetic for teaching in the first school years, São Paulo (1961-1996). To approach the professional knowledge of the teacher who teaches mathematics is the theme of this project which seeks to make intelligible the role of experts in the systematization of an arithmetic for teaching. This text presents the first analyzes of the production of Lydia Lamparelli, constituted as expert, from bibliographical references taken for this study. The first results reveal possibilities that personal arquives can give to the characterization of the professional knowledge of the teacher who teaches mathematics.

Keywords: Knowledge for teaching. Arithmetics. Lydia Lamparelli. Expert. Personal arquives.

\section{Résumé}


Cet article présente les résultats partiels d'un projet de recherche intitulé Les experts et l'arithmétique pour l'enseignement dans les premières années scolaires, São Paulo (1961-1996). Considérer le savoir professionnelle de l'enseignant des mathématiques est le thème de ce projet qui cherche à rendre intelligible le rôle des experts dans la systématisation d'une arithmétique pour enseigner. Ce texte présente les premières analyses de la production de Lydia Lamparelli, constituée en expert, à partir des références bibliographiques prises pour cette étude. Les premiers résultats révèlent des possibilités que les archives personnelles peuvent donner à la caractérisation des savoirs professionnelles de l'enseignant qui enseigne les mathématiques.

Mots-clés: Savoir enseigner. Arithmétique. Lydia Lamparelli. Expert. Archives personnels.

\section{Considerações iniciais}

O Grupo de Pesquisa de História da Educação Matemática no Brasil (GHEMAT), ao longo dos seus 18 anos de existência, vem se caracterizando pelo trabalho desenvolvido por meio de projetos coletivos de pesquisa. Durante esse tempo, diversas investigações foram desenvolvidas pelo Grupo, possibilitando a integração de dezenas de pesquisadores em torno de temáticas comuns investigadas ${ }^{3}$. Assim reunidos, os diferentes pesquisadores elaboram estudos específicos vinculados a um tema geral de um projeto de maior amplitude, o que se entende, comumente, por "projeto guarda-chuva".

Em tempo recente, o GHEMAT vem se debruçando sobre a temática dos saberes profissionais da docência, mobilizando novos referenciais teórico-metodológicos para esse trabalho. Ao que tudo indica, por meio de levantamentos bibliográficos, tais referentes para a pesquisa ainda não foram mobilizados em estudos brasileiros. Como já é característica desse Grupo trabalhar com projetos de âmbito coletivo, a proposta de investigação dos saberes profissionais foi submetida à Fundação de Amparo à Pesquisa do Estado de São Paulo (FAPESP), na modalidade projeto temático.

3 Citem-se como estudos de maior envergadura as pesquisas em cooperação internacional com Portugal, no período 2006 a 2009, em torno do projeto "A matemática moderna nas escolas do Brasil e de Portugal: estudos históricos comparativos" (CAPES-GRICES); e, também de caráter internacional, as investigações desenvolvidas junto com a França, por meio de financiamento CAPES-COFECUB, na realização do projeto "O ensino de matemática na escola primária nos séculos XIX-XX: estudos comparativos entre o Brasil e a França" ocorrido entre os anos de 2014 e 2017. Para além desses projetos, o CNPq tem auxiliado os estudos do Grupo, por meio de Editais Universais, em faixa de maior financiamento. Todos esses projetos tiveram a participação de cerca de duas dezenas de pesquisadores-doutores brasileiros, de diferentes estados, reunidos a pesquisadores estrangeiros. 
O estudo, intitulado "A Matemática na Formação de Professores e no Ensino: processos e dinâmicas de produção de um saber profissional, 1890-1990", logrou aprovação e financiamento dessa Fundação ${ }^{4}$.

Nos termos desse "projeto guarda-chuva" - pela FAPESP, denominado "projeto temático" - tem-se como problemática maior de pesquisa a caracterização da matemática como um saber profissional da docência, que ao longo do tempo vem sendo elaborada, sistematizada sob rubricas que vão cada vez mais tendo status epistemológico de saber, revelando-se como uma matemática para ensinar, articulada a uma matemática para ensinar (Valente et al., 2017).

Tal caracterização desses saberes matemáticos, vistos sob a ótica de dois regimes de saber, tem por referência os estudos de Hofstetter e Schneuwly (2017), onde saberes ligados ao ensino e à formação diferenciam-se por suas especificidades e assim são definidos, para a docência: "os saberes a ensinar, ou seja, os saberes que são objetos do seu trabalho; e os saberes para ensinar que são as ferramentas do seu trabalho" (Hofstetter, Schneuwly, 2017, p. 132, grifos dos autores). Nesse sentido, tais autores suíços demarcam os saberes em dois campos distintos, porém articulados. Tais saberes, dentro de suas especificidades, cumprem a função de formar alunos e professores.

Assim, o projeto temático considera, por hipótese de trabalho, em seu quadro teórico-metodológico, a existência de uma matemática advinda do saber a ensinar e outra elaborada pelos saberes a ensinar, assim admitindo a existência de diferentes matemáticas (Valente et al., 2017, p. 20).

Cabe ainda explicitar aqui, nesta introdução, categorias que o projeto intenta mobilizar, que são os saberes profissionais, saberes objetivados, sistematização dos saberes e sua institucionalização. De acordo com Valente et al. (2017):

No caso dos saberes profissionais, refere-se a expressão aos saberes de formação de professores dado pela articulação entre os saberes a ensinar e os saberes para ensinar [...]. Relativamente aos saberes objetivados tal conceituação leva em conta os pressupostos dos estudos de Hofstetter e Schneuwly (2009) que tomam os saberes de modo distinto daqueles tratados nos estudos que abordam o ponto de vista da prática, considerando sua mobilização no fazer, na ação. Em contrapartida, tais autores suíços colocam acento nos saberes formalizados - os saberes objetivados - de maneira que, por meio deles, seja possível construir uma sistematização com vistas a conceitualizar o seu papel nas profissões do ensino e da formação. Por "sistematização de saberes" entenda-se o processo histórico que elabora saberes objetivados conceituando-os. E, finalmente, por "institucionalização de saberes" tem-se as dinâmicas que envolvem os saberes

4 Projeto Temático sendo desenvolvido com auxílio da Fundação de Amparo à Pesquisa do Estado de São Paulo (FAPESP), coordenado pelo Prof. Dr. Wagner Rodrigues Valente (UNIFESP - Campus Guarulhos, SP) (Processo 2017/15751-2). Também integram o projeto, como pesquisadoras associadas, as professoras Luciane de Fátima Bertini (UNIFESP - Campus Diadema), Neuza Bertoni Pinto (REAMEC) e Rosilda dos Santos Morais (UNIFESP - Campus Diadema). Para maiores informações consulte-se: http://www.bv.fapesp.br/pt/auxilios/98879/amatematica-na-formacao-de-professores-e-no-ensino-processos-e-dinamicas-de-producao-de-um-saber-p/ 
objetivados transformando-os em rubricas presentes nas instituições de ensino e de formação de professores (Valente et al., 2017, p. 9-10).

O longo excerto acima, extraído do texto do projeto temático, alinha os conceitos advindos dos "referenciais suíços" 5 e mobiliza-os de modo a tratá-los como lentes para a leitura da empiria da pesquisa. Tal mobilização é considerada indispensável para se chegar ao objetivo principal do projeto, que consiste em "Investigar os processos e dinâmicas de constituição do saber profissional do professor que ensina matemática no período compreendido entre 1890-1990" (Valente et al., 2017, p. 30).

Sendo o projeto temático caracterizado por um tema de trabalho muito abrangente, a pesquisa necessitou ser organizada em diferentes eixos para seu desenvolvimento. Em cada um deles, estão vinculados subprojetos de iniciação científica, mestrado, doutorado e pós-doutorado. As temáticas individuais convergem seu foco de investigação para um mesmo objetivo, que é o saber profissional do professor que ensina matemática.

Este presente artigo é fruto de pesquisas que vêm sendo realizadas no âmbito do primeiro eixo, no desenvolvimento do subprojeto intitulado Os experts e a aritmética para ensinar nos primeiros anos escolares, São Paulo (1961-1996), uma pesquisa de doutoramento.

Este eixo visa compreender como a matemática a ensinar e a matemática para ensinar estiveram presentes em diferentes momentos históricos e quais sistematizações foram realizadas e chanceladas por aqueles que passaram a ser considerados como experts da educação matemática. Os eixos seguintes são caracterizados por trazer à baila as discussões que envolvem a constituição das diferentes rubricas presentes nos primeiros anos escolares, que envolvem a matemática, bem como aquelas que abarcam as disciplinas de formação matemática dos professores. Tais eixos da pesquisa intitulam-se, respectivamente, "Processos de elaboração da matemática a ensinar nos primeiros anos escolares" e "A matemática na formação de professores para os primeiros anos escolares: a constituição da matemática para ensinar". O quarto eixo do projeto reúne "a produção realizada no espaço escolar que conjuga a interação entre professores, alunos e saberes" e recebe o nome de "Professores que ensinam matemática e a matemática ensinada" (Valente et al., 2017, p. 33).

Retomando as considerações mencionadas anteriormente, enfatize-se que ao tratar da formação de professores, tendo em conta a centralidade dos saberes, constituemse como ferramentas dessa formação do professor, os saberes para ensinar. Esses

5 O projeto temático tem como um de seus principais referenciais teóricos os trabalhos desenvolvidos pelos pesquisadores da Equipe de Pesquisa em História das Ciências da Educação (ERHISE) da Universidade de Genebra, Suíça. Para maiores informações sobre essa equipe, acessar https://www.unige.ch/fapse/erhise/ 
saberes estão sendo investigados por meio de uma literatura cinzenta ${ }^{6}$ encontrada em acervos pessoais de professores que trabalharam na formação de outros professores, e que foram se constituindo como experts. Nesse sentido, cabe lembrar, como fazem Hofstetter e Schneuwly (2017, p.133) que "formar, como qualquer atividade humana, implica dispor de saberes para sua efetivação, para realizar essa tarefa, esse ofício específico". Estudar estes saberes para ensinar pela via dos experts incide o enfoque da pesquisa sobre as práticas de ensino e sobre a instituição dos saberes profissionais do professor que ensina matemática. Este artigo apresenta resultados parciais desse tipo de investigação. Em particular, o texto tece considerações sobre documentos encontrados no acervo pessoal da professora Lydia Lamparelli.

\section{Expert e expertise}

O termo expert remonta à Grã-Bretanha das primeiras décadas do século XIX. Ele liga-se à necessidade dos governos de um assessoramento especializado para 0 trato de problemas práticos da vida social, tais como: o saneamento das cidades, o planejamento urbano, a administração das contas públicas dentre outras demandas (Burke, 2017, p. 62).

Hofstetter et al. (2017) em capítulo intitulado "Penetrar na verdade da escola para ter elementos concretos de sua avaliação - A irreversível institucionalização do expert em educação (século XIX e XX)", discutem o processo de constituição desse profissional da educação e de ações inerentes a seu ofício, tratam historicamente do expert em educação. Este capítulo é constituinte da obra: "Saberes em (trans) formação: tema central da formação de professores, que tem como organizadores Rita Hofstetter e Wagner Rodrigues Valente, lançado recentemente no Brasil, em 2017. Registre-se que a obra traz, com tradução para o português, junto ao estudo sobre os experts em educação, uma série de trabalhos desenvolvidos por pesquisadores da Universidade de Genebra.

Os estudos realizados por Hofstetter et al. (2017) apontam para a "evolução da produção de saberes no campo pedagógico nos séculos XIX e XX". Tais saberes em transformação são verificados com a emergência do expert em educação, profissional este imbuído de atribuições, com diferentes perfis e produções, que definem formas de expertise (Hofstetter et al., 2017, p. 55-56). O estudo analisa a institucionalização desta expertise, tendo o Estado como responsável pela instrução pública.

6 A Quarta Conferência Internacional sobre Literatura Cinzenta (GL'99), realizada em Washington, DC, em outubro de 1999, definiu literatura cinzenta como: "O que é produzido em todos os níveis do governo, institutos, academias, empresas e indústria, em formato impresso e eletrônico, mas que não é controlado por editores científicos ou comerciais." Disponível em: <http://ses.sp.bvs.br/local/File/literatura\%20cinzenta trad.pdf >. Acesso em 15 de abril de 2013. 
Sob a ótica defendida por estes autores, a constituição de um expert atende a dois requisitos básicos. $O$ primeiro diz respeito à necessidade desse profissional se destacar em seu ofício, pelos saberes que lhe são próprios para a condução de seu trabalho, como por exemplo, os saberes científicos e os saberes da experiência. O segundo requisito é que além de necessitar ter a posse desses saberes, este profissional deverá ocupar um cargo, posto, cadeira etc. e a ele é permitido, por meio desse posto, sistematizar saberes específicos para o funcionamento escolar, tais como a elaboração de programas para o ensino, cursos para os professores, além de outras atividades que estejam ligadas à sua expertise.

Cabe aqui também destacar o termo expertise, conceito que pode ser entendido por um conjunto de saberes necessários que o expert deve possuir para constituir sua função. Hofstetter et al. (2017) melhor caracterizam os termos ao tratarem o expert como tendo lugar numa

[...] instância, em princípio, reconhecida como legítima, atribuída a um ou a vários especialistas - supostamente distinguidos pelos seus conhecimentos, atitudes, experiências - , a fim de examinar uma situação, de avaliar um fenômeno, de constatar fatos. Esta expertise é solicitada pelas autoridades do ensino tendo em vista a necessidade de tomar uma decisão (Hofstetter et al., 2017, p. 57).

Percebe-se no trecho acima uma reafirmação da relação existente entre expert e expertise, condição necessária para que o expert possa ser reconhecido no exercício de seu cargo. Deve-se enfatizar ainda que, essa instância, considerada como legítima, tem a função se sistematizar saberes em busca de um saber cada vez mais padronizado, passível de ganhar circulação e ser utilizado nos meios escolares, o que nos leva a um saber objetivado (Hofstetter et al., 2017).

Ao admitir que os saberes sempre estão em contínua transformação, como o próprio título da obra de Hofstetter e Valente (2017) sugere, o trabalho de uso de uma expertise não está ligado em transformar os saberes teóricos, vindos das ciências específicas das disciplinas. Estes saberes, produzidos por experts, vão se decantando e sendo (re)elaborados no afã de possuírem características de um saber pragmático e próprio da profissão (Hofstetter et al., 2017, p. 68).

Está posto também, por Hofstetter et al. (2017), que a expertise é tratada como uma instância que evolui constantemente no sentido de uma crescente institucionalização. Isso se deve sobremaneira ao constante dinamismo do sistema escolar e do Estado, que evoluem em marcha de sua organização, provocada pelos diferentes atores que atuam neste sistema. Assim, a contínua marcha rumo à profissionalização docente lança mão de saberes e, ao mesmo tempo, vê, por meio dos experts, a sistematização deles, num movimento de idas e vindas às necessidades impostas pelo meio escolar.

Desse modo, segundo Hofstetter et al. (2017), "o trabalho de expertise se aperfeiçoa 
e desenvolve fortemente os saberes que lhe dizem respeito; procedimentos, análises, testes tornam-se um produto coletivo", tornando os saberes cada vez mais codificados e padronizados (Hofstetter et al., 2017, p. 68). Assim, a elevação de um personagem à condição de expert, por sua expertise reconhecida, promoverá o desenvolvimento dessa própria expertise em termos da produção de novos saberes autorizados e legitimados pela função e cargo ocupados pelo expert.

Em relação à educação matemática, Bertini, Morais e Valente (2017) consideram que já havia experts sendo constituídos no âmbito deste ensino no século XX, no Brasil, coincidindo com o período de investigação dos estudos realizados pelos pesquisadores suíços. Na obra escrita por esses autores, é possível acompanhar etapas da progressiva marcha de institucionalização dos experts e da sistematização das expertises ligadas ao ensino de matemática.

A mobilização dos conceitos de expert e expertise permite que se possa analisar como, ao longo do tempo, ocorrem processos e dinâmicas de elaboração do saber profissional da docência. Em particular, interessa-nos o uso desse aparato teóricometodológico para estudo da constituição do saber profissional do professor que ensina matemática nos primeiros anos escolares.

Como se apresentam, constituem-se e como são reveladas sistematizações da matemática para ensinar? Desenvolveremos neste artigo o estudo de um caso brasileiro, particularmente da cidade de São Paulo, tendo em conta a atuação da professora Lydia Condé Lamparelli, perante os órgãos oficiais de ensino paulista. Mostraremos que esta professora constituiu-se como uma expert para assuntos educacionais ligados ao ensino de matemática. Tomaremos um documento de seu acervo - que consideramos emblemático - para análise dos processos de elaboração de uma matemática para ensinar.

\section{Lydia Condé Lamparelli: uma expert do ensino público paulista}

Lydia Condé Lamparelli é uma professora paulistana que deixou suas marcas profissionais no ensino público de São Paulo nas décadas de 1960, 70 e 80, por meio de projetos de formação de professores, livros didáticos e materiais instrucionais para professores, entre outras atividades desenvolvidas por ela, em instituições onde foi constituída sua expertise profissional.

Já há estudos sobre a biografia de Lydia Lamparelli em dois trabalhos que investigaram a sua trajetória profissional. O primeiro deles refere-se à tese defendida por Gilda Lucia Delgado de Souza, em 2005, na Faculdade de Educação da Universidade de Campinas (FE-UNICAMP), intitulada "Educação matemática na CENP: um estudo histórico sobre 
condições institucionais de produção cultural por parte de uma comunidade de prática". Souza (2005) investigou em seu trabalho as circunstâncias que levaram à constituição da Coordenadoria de Ensino e Normas Pedagógicas (CENP), órgão da Secretaria Estadual de Educação do Estado de São Paulo; como, também, a formação e atuação da equipe de Matemática no período de 1976 a 1983. Para isso, entrevistou oito professores que fizeram parte da equipe da CENP no intento de "captar em cada indivíduo em particular, institucionalmente situado, seus pontos de vista e participações na produção de práticas educativas relativas à Educação Matemática paulista" (Souza, 2005, p. 2). Por meio dos discursos desses educadores e documentos textuais, a autora do estudo conta a história desse órgão, com abrangência aos aspectos de transformações dos conteúdos disciplinares do ensino de Matemática.

Uma das professoras entrevistadas nessa tese é Lydia Lamparelli, que trabalhou com a equipe na produção de documentos da CENP, buscando desenvolver o material intitulado "Atividades Matemáticas 1 e 2", a partir do estágio realizado por ela no Institut National de Recherches et Documentation Pédagogiques (INRDP) - França (Souza, 2005, p. 164).

A experiência com livros didáticos de Lydia Lamparelli, segundo Souza (2005), começa no tempo em que fazia parte do Instituto Brasileiro de Educação, Ciência e Cultura (IBECC), que foi criado como Comissão Nacional da Organização das Nações Unidas para a Educação, a Ciência e a Cultura (UNESCO), no Brasil. O contato com as obras do School Mathematics Study Group (SMSG) possibilitou à Professora Lydia o primeiro contato com um "novo tipo de ensino da Matemática" (Souza, 2005, p.142), na tarefa de traduzir e adaptar essas obras para o ensino de matemática no Brasil.

Um outro trabalho sobre Lydia Lamparelli refere-se a um capítulo do livro "Educadoras Matemáticas: memória, docência e profissão", organizado por Wagner Rodrigues Valente. No texto dedicado à Lydia Lamparelli, os autores Antônio José Lopes e Denise Medina trataram de aspectos pessoais e profissionais dessa professora, à luz de entrevista por ela concedida a esses pesquisadores. O capítulo traz como referência trabalhos anteriores, como a dissertação de mestrado de Denise Medina, um das autoras do capítulo, defendida em 2007, na Pontifícia Universidade Católica de São Paulo (PUC-SP), intitulada "A produção oficial do Movimento da Matemática Moderna para o ensino primário do Estado de São Paulo (1960-1980)", além do estudo de Souza (2005), já descrito anteriormente.

De acordo com Lopes e Medina (2013), o início da carreira profissional de Lydia Lamparelli coincidiu com intensas mudanças ocorridas nos programas e no currículo das escolas, decorrentes com a introdução dos estudos desenvolvidos por Jean Piaget sobre aprendizagem e metodologias alternativas, e na penetração do ideário do Movimento da Matemática Moderna no Brasil.

A expertise de Lydia Lamparelli se deu em traduções, adaptações e autoria de livros 
didáticos; traduções de artigos e documentos sobre educação, psicologia, educação matemática, matemática, dentre outras atividades inerentes ao ofício docente. Há diversas citações e apropriações que Lydia Lamparelli fez dos estudos de Jean Piaget, registrados em documentos por ela escritos e em documentos do seu acervo pessoal.

Por meio da história profissional de Lydia Lamparelli, é possível perceber o seu status de especialista, tendo em conta as formas de expertise a ela atribuídas.

Em 2017, Lydia Lamparelli autorizou a divulgação de parte de seu acervo pessoal no Repositório Institucional da Universidade Federal de Santa Catarina (UFSC), espaço virtual onde está depositado o material empírico que serve de fonte às pesquisas do GHEMAT. Nesse acervo digitalizado encontram-se 59 documentos de diversos tipos do acervo de Lamparelli. Tais documentos pertencem a diferentes épocas e têm natureza variada, como por exemplo, livros destinados a professores editados em outras línguas (inglês e francês), materiais utilizados em cursos para professores, apostilas com conteúdo matemático, textos com conteúdo pedagógico, traduções, entre outros materiais destinados à formação de professores.

\section{A expertise de Lydia Lamparelli posta a serviço da elaboração de textos destinados a professores}

Em análise preliminar, já é possível extrair alguns elementos que revelam características do trabalho de Lydia Lamparelli, em textos destinados à formação de professores do estado de São Paulo. Dentre os 59 documentos até agora inventariados e disponíveis no Repositório - como literatura cinzenta - cinco são de própria autoria de Lydia Lamparelli, intitulados "A falsa posição entre o concreto e o abstrato", "O sentido da matemática na pré-escola", "Didática das Matemáticas Elementares", "Reflexão sobre a Metodologia da Matemática" e "Considerações sobre a avaliação da aprendizagem matemática no ciclo básico".

Neste artigo, vamos nos debruçar na análise do primeiro texto mencionado, intitulado "A falsa posição entre o concreto e o abstrato", que foi chancelado pela Coordenadoria de Estudos e Normas Pedagógicas (CENP), em 1985. Não deixa de chamar à atenção, inicialmente, no cabeçalho do texto, antes da referência à CENP, o título "Governo Democrático de São Paulo", remetendo ao tempo em que foram reestabelecidas as eleições diretas para os governos estaduais, em 1984, sendo eleito, em São Paulo, André Franco Montoro.

O documento tem apenas quatro páginas, na forma de apostila, mimeografada. O estudo revela o esforço de Lamparelli em tornar acessível aos professores o entendimento do par conceitual concreto-abstrato à luz de estudos considerados de 
vanguarda à época.

No documento, Lydia Lamparelli parte da ideia comumente difundida de que a "Matemática é vista como uma disciplina que não permite a pesquisa, a iniciativa e a manipulação por parte do aluno, sendo uma ciência abstrata". E, ainda, que a ideia de manipular seria, num entendimento geral, manipular objetos (Lamparelli, 1985).

Num primeiro momento, a autora trava conversa com o estabelecido no âmbito escolar desde há muito tempo: há necessidade de partir do concreto, entendido como rol de materiais empíricos, manipuláveis:

Assim, aceitando-se que, para que um aluno venha, verdadeiramente, dispor das ferramentas matemáticas não basta a explicação do professor e a aprendizagem mecânica de regras, privilegia-se, então, o papel do aluno na construção do seu saber e, quase que naturalmente, somos atraídos pelos métodos ativos que, via de regra, desembocam na "pedagogia do concreto". Dessa forma, as situações pedagógicas consideradas válidas são aquelas que possibilitam a utilização de "materiais concretos" para que os alunos, ao manipulá-los, façam a passagem do concreto ao abstrato (Lamparelli, 1985, p. 2).

$\mathrm{Na}$ análise dessa situação, desse modo de tratar o concreto pelos professores, Lydia Lamparelli pondera que estão implícitas várias premissas. Dentre elas, tem-se a admissão de que o concreto "é aquilo que se pode ver e tocar, pois os chamados 'materiais concretos' privilegiam quase que, exclusivamente, os sentidos da visão e do tato"; uma outra é que "manipular é sinônimo de 'manipular objetos sensíveis'"; uma terceira trabalha com a ideia de que "basta manipular objetos sensíveis para que a construção dos conceitos aconteça" (Lamparelli, 1985, p. 2-3).

De fato, estudos históricos posteriores revelam como tais ideias - premissas mencionadas pela Professora Lydia, enraízam-se e passam a compor elementos da chamada "cultura escolar", conceito elaborado por teóricos como Dominique Julia (2001)7. Um desses estudos, de Valente (2017), analisa a frase constantemente ouvida nos meios escolares: "eu trabalho primeiro no concreto". No estudo histórico realizado, o autor pondera que:

O tema do "ensino primeiro no concreto" tem sido abordado por vários estudos na atualidade. Seja tratado de modo direto, seja por meio de pesquisas que envolvem formas alternativas do ensino de matemática como, por exemplo, os laboratórios de ensino de matemática. Ao que tudo indica, é em finais do século XIX que a cultura escolar incorpora o "ensino primeiro no concreto", tendo esse elemento presença até os dias de hoje. Um elemento da cultura escolar (Valente, 2017, p. 608).

7 Em síntese, fazendo referência a Julia (2001), a cultura escolar em uma perspectiva abrangente, engloba "um conjunto de normas que definem conhecimentos a ensinar e condutas a inculcar, e um conjunto de práticas que permitem a transmissão desses conhecimentos e a incorporação desses comportamentos; normas e práticas coordenadas a finalidades que podem variar segundo as épocas" (p. 10). 
Valente (2017) mostra, na análise do impacto da pedagogia intuitiva nas escolas, que "é preciso concretizar". E tal prática tem referência nas lições que as coisas dão, às lições de coisas ${ }^{8}$. Assim, "trabalhar no concreto" segue da manipulação de objetos do mundo físico para representações ${ }^{9}$ abstratas desse mundo, por exemplo, por meio dos objetos matemáticos.

A leitura realizada por Lydia Lamparelli dos elementos da cultura escolar com os quais ela estava lidando, ao tratar da formação de professores nos anos 1980, revela o cuidado da autora em bem caracterizar quais poderosas ideias precisavam ser debatidas para serem transformadas. Ideias presentes na cultura escolar, representações-guias das práticas pedagógicas dos professores. Assim, era preciso dialogar com os docentes e buscar romper com essas representações - no caso, a representação do concreto para o trabalho pedagógico. Na ruptura intentada, a Professora Lydia realiza o movimento de construção de novas representações advindas dos estudos considerados avançados sobre o ensino de matemática.

Quando Lydia Lamparelli coloca-se em marcha para o debate que visa dar novo significado para o par concreto-abstrato tão importante nos ensinos escolares, em especial na docência de matemática, menciona o diagnóstico realizado na cultura escolar, apresentando como "equívocos". Dessa forma, ela destaca que os professores equivocam-se ao tratarem o concreto como o empírico sensível. Sendo assim, caberá superar tal visão. E a nova concepção que deverá viger tratará o concreto de outro modo:

Concreto não é um conceito que encerra uma ideia absoluta, isto é, ele jamais é dado isoladamente; ele está intimamente relacionado à abstração. Assim, o "concreto" pode ser concebido como um ponto de partida intuitivo onde o novo conhecimento a ser elaborado deve se apoiar. Não é, portanto, necessariamente, "aquilo que se pode tocar e ver". Por exemplo: para os alunos de uma 5. ${ }^{a}$ série, os números naturais podem se constituírem em um concreto, mediante o qual elaboram novos conceitos, isto é, atingem novas abstrações. O que é abstrato num nível, passa a ser concreto em outro. Assim há diferentes níveis de concreto e abstrato (Lamparelli, 1985, p. 3).

Desse modo, continua a Professora Lydia, deve-se pensar as práticas pedagógicas tendo em conta um novo significado para o concreto; e com ele, modifica-se, também, a ideia de manipular:

8 A Primeiras Lições de Coisas é uma obra clássica que circulou no Brasil, cuja primeira versão foi publicada nos Estados Unidos em 1861 de autoria de Norman Alison Calkins e traduzida para o português por Rui Barbosa em 1886. Este manual tem sido utilizado por pesquisadores que investigam a escola primária brasileira do início do século XX, mais especificamente o ensino intuitivo, como se pode encontrar nos estudos de Valdemarin (2004).

9 Neste ponto, cabe precisar um conceito vindo da História Cultural: de representação. Trata-se de construto teórico utilizado nos estudos do historiador Roger Chartier. Assim, entenda-se tal conceito como o "modo como em diferentes lugares e momentos uma determinada realidade social é constituída, pensada, dada a ler" (Chartier, 1990, p. 16-17). 
O concreto, ganhando esta nova dimensão, acarreta a manipulação do que se entende por manipular. Para que todo conhecimento se apoie em imagens ou formas intuitivas, manipular não significa apenas "manipular objetos sensíveis", mas também agir sobre representações, símbolos e escritas matemáticas (Lamparelli, 1985, p. 3).

Por último, o documento traz uma frase da autora, tomada como citação de Pierre Greco ${ }^{10}$ : "a matemática não está nas coisas, mas naquilo que fazemos com elas". A partir dessa citação, a Professora Lydia concluirá: "a simples manipulação não garante a construção do conhecimento, embora seja importante agir de início na esfera do intuitivo" (Lamparelli, 1985, p. 3).

A página final do documento está reservada à bibliografia, lá estão presentes autores como Ferdinand Gonseth, Jean Piaget e estudos da Équipe de Recherche Mathématique à l'école élémentaire, de Paris.

\section{Considerações finais}

Retomemos nestes apontamentos finais a problemática que envolveu este artigo. Ela ligou-se às possibilidades que acervos pessoais, por meio de uma literatura cinzenta, podem dar em termos do melhor entendimento dos saberes de formação dos professores, dos saberes que irão caracterizar a sua formação profissional, dos saberes profissionais. Neste texto, os saberes profissionais são concebidos como saberes para ensinar. E, especificamente tratando da docência da matemática, tais saberes podem ser pensados como sendo uma matemática para ensinar. Como essa matemática é elaborada ao longo do tempo? Tal questão pode ter uma via de resposta na análise do papel exercido pelos experts. Tais personagens revelam-se como muito importantes para a compreensão de como são sistematizados elementos constituintes de uma matemática para a docência, uma matemática para ensinar. O expert se define por assessorar governos, e essa assessoria tem num primeiro momento um diálogo com as demandas dos órgãos oficiais, demandas práticas que a sociedade está necessitando; no entanto, será na expertise colocada em ação - de modo sistematizado - na orientação dos professores, que resultará no que o governo espera da contratação desse profissional.

O documento analisado revela um tempo em que estão em discussão, sobretudo,

10 Pierre Greco (1927 - 1988) pertenceu ao grupo de colaboradores de Jean Piaget. Alguns de seus trabalhos com outros pesquisadores em epistemologia genética intitulam-se Aprendizagem e Conhecimento (1959), A lógica do aprendizado (1959), Problemas da construção do número (1960), Estruturas digitais básicas (1962), A formação de raciocínio corrente (1963), A epistemologia do espaço (1964) e Percepção de noção e tempo (1967). Disponível em < http://www.fondationjeanpiaget.ch/fjp/site/bibliographie/index_EEG.php>. Acesso em 18-052018. 
as ideias piagetianas; um tempo de necessidade de sedimentação dessas ideias nas práticas pedagógicas. Como trazer Piaget para a sala de aula? Como dialogar com os professores de modo que seja possível a construção de um saber pragmático para a docência? Como a visão sobre a matemática na escola deverá ser transformada de modo que o Governo do Estado revele estar em dia, atualizado com a formação de professores do ensino público, da rede escolar paulista? O papel exercido pela Professora Lydia, e não somente por ela, por certo, por toda a equipe da CENP, é de fundamental importância e buscará dar resposta a todas essas questões.

O documento analisado, curto, sem amarras acadêmicas, sem citações rebuscadas, vai direto ao ponto crucial: colocar em xeque, diante de novos modos de pensar o ensino e aprendizagem da matemática, as formas antigas vindas do final do século XIX, enraizadas na cultura escolar, da vaga pedagogia intuitiva. Desse modo, a discussão do par concreto-abstrato mostra-se fundamental. $O$ texto dirigido aos professores revela a ação do expert em termos de construção de um saber pragmático para a profissão. Não caberia reescrever conceitos, organizar longos textos aos docentes. Um simples exemplo será suficiente para fazer valer a ideia central: o conjunto dos números naturais poderá ser visto como "o concreto" para aprendizagens matemáticas futuras. Tal exemplo revela uma fala direta com o professor, mostra-lhe uma nova matemática, a necessidade de que o professor possa aparelhar-se com ela, de modo a atualizar o seu saber profissional, agora não mais ligado à ideia de que matemática se aprende com o concreto empírico, manipulável fisicamente. Instala-se um novo saber para ensinar, uma nova matemática para ensinar, novas ferramentas para a docência, um novo saber profissional.

\section{Referências bibliográficas}

Bertini, L.F.; Morais, R.S.; Valente, W.R. (2017). A Matemática a ensinar e a Matemática para ensinar: novos estudos sobre a formação de professores. São Paulo: Editora Livraria da Física.

Burke, P. (2017). O que é história do conhecimento? Trad. Claudia Freire. São Paulo: Editora da Unesp.

Chartier, R. (1990). A história cultural - entre práticas e representações. Lisboa: Difel; Rio de Janeiro: Bertrand Brasil S.A.

Hofstetter, R. \& Valente, W. R. (2017). Saberes em (trans)formação - tema central da formação de professores. São Paulo: Livraria Editora da Física. 
Hofstetter, R. et al. (2017). Penetrar na verdade da escola para ter elementos concretos de sua avaliação - A irresistível institucionalização do expert em educação (século XIX e XX). Trad. Marcos Denilson Guimarães e Wagner Rodrigues Valente. In: Hofstetter, R.; Valente, W. R. (Orgs.). Saberes em (trans)formação: tema central da formação de professores. $1^{a}$ ed. São Paulo: Editora Livraria da Física (Coleção Contextos da Ciência), p. 55-112.

Julia, D. (2001). A cultura escolar como objeto histórico. Revista Brasileira de História da Educação. Campinas, SP, n. 1, p. 9-43.

Lamparelli, L.C. (1985). A falsa oposição entre o concreto e o abstrato. São Paulo: Governo Democrático do Estado de São Paulo. Retirado em 18 de abril, 2018, de https://repositorio.ufsc.br/handle/123456789/172749.

Souza, G.L.D. (2005). Educação matemática na CENP: um estudo histórico sobre condições institucionais de produção cultural por parte de uma comunidade de prática. Tese de Doutorado, Programa de Pós-Graduação em Educação Matemática, Universidade de Campinas, Campinas, Brasil.

Valente, W.R. et al. (2017). A Matemática na Formação de Professores e no Ensino: processos e dinâmicas de produção de um saber profissional, 1809-1990. Projeto de Pesquisa. São Paulo: FAPESP. Recuperado em: 10 de abril, 2018, de http:// bv.fapesp.br/pt/auxilios/98879/a-matematica-na-formacao-de-professores-e-noensino-processos-e-dinamicas-de-producao-de-um-saber-p/?q=17/15751-2

Valente, W. R. (2017). "Matemática? Eu trabalho primeiro no concreto": elementos para a história do senso comum pedagógico - Ciênc. Educ., Bauru, v. 23, n. 3, p. 597611. https://doi.org/10.1590/1516-731320170030004.

André Francisco de Almeida é Doutorando em Ciências pela Universidade Federal de São Paulo, Campus Guarulhos, SP. E-mail: afdealmeida@gmail.com

Wagner Rodrigues Valente é Professor Livre Docente do Departamento de Educação da Escola de Filosofia, Letras e Ciências Humanas da UNIFESP, Campus Guarulhos, SP. Coordenador do GHEMAT-SP, www.ghemat.com.br E-mail: ghemat.contato@gmail.com 